\title{
Loss of Function of the Nuclear Receptor NR2F2, Encoding COUP-TF2, Causes Testis Development and Cardiac Defects in 46,XX Children
}

Anu Bashamboo, ${ }^{1}$ Caroline Eozenou, ${ }^{1}$ Anne Jorgensen, ${ }^{2}$ Joelle Bignon-Topalovic, ${ }^{1}$ Jean-Pierre Siffroi, ${ }^{3}$ Capucine Hyon, ${ }^{3}$ Attila Tar, ${ }^{4}$ Péter Nagy, ${ }^{5}$ Janos Sólyom, ${ }^{6}$ Zita Halász, ${ }^{6}$ Annnabel Paye-Jaouen, ${ }^{7}$ Sophie Lambert, ${ }^{8}$ David Rodriguez-Buritica, ${ }^{9}$ Rita Bertalan, ${ }^{1}$ Laetitia Martinerie, ${ }^{8}$ Ewa Rajpert-De Meyts, ${ }^{2}$ John C. Achermann, ${ }^{10}$ and Ken McElreavey ${ }^{1, *}$

Emerging evidence from murine studies suggests that mammalian sex determination is the outcome of an imbalance between mutually antagonistic male and female regulatory networks that canalize development down one pathway while actively repressing the other. However, in contrast to testis formation, the gene regulatory pathways governing mammalian ovary development have remained elusive. We performed exome or Sanger sequencing on 79 46,XX SRY-negative individuals with either unexplained virilization or with testicular/ovotesticular disorders/differences of sex development (TDSD/OTDSD). We identified heterozygous frameshift mutations in NR2F2, encoding COUP-TF2, in three children. One carried a c.103_109delGGCGCCC (p.Gly35Argfs*75) mutation, while two others carried a c.97_103delCCGCCCG (p.Pro33Alafs*77) mutation. In two of three children the mutation was de novo. All three children presented with congenital heart disease (CHD), one child with congenital diaphragmatic hernia (CDH), and two children with blepharophimosis-ptosis-epicanthus inversus syndrome (BPES). The three children had androgen production, virilization of external genitalia, and biochemical or histological evidence of testicular tissue. We demonstrate a highly significant association between the NR2F2 loss-of-function mutations and this syndromic form of DSD $\left(\mathrm{p}=2.44 \times 10^{-8}\right)$. We show that COUP-TF2 is highly abundant in a FOXL2-negative stromal cell population of the fetal human ovary. In contrast to the mouse, these data establish COUP-TF2 as a human "pro-ovary" and "anti-testis" sex-determining factor in female gonads. Furthermore, the data presented here provide additional evidence of the emerging importance of nuclear receptors in establishing human ovarian identity and indicate that nuclear receptors may have divergent functions in mouse and human biology.

The sex chromosomes of an individual usually direct gonadal sex development toward either a testis or ovary pathway. In 46,XY individuals, the presence of the $\mathrm{Y}$ chromosome testis-determining gene SRY (MIM: 601947) triggers a genetic cascade that both initiates testis formation and represses the formation of the ovary. ${ }^{1}$ Although many factors are known to be involved in early testis development, far less is known about genetic factors controlling the ovary. ${ }^{1}$ However, emerging evidence suggests that ovary development involves more than just a default (passive) pathway, ${ }^{2}$ consistent with the $Z$-factor theory proposed 25 years ago that the XX gonad expresses an elusive factor that actively promotes both "anti-testis" and "pro-ovary" functions. ${ }^{3}$

The genomic analysis of 46,XX individuals with testes (sometimes known as testicular disorders/differences of sex development [TDSD]; [MIM: 400045]) or ovotestes (ovotesticular DSD [OTDSD]) supports the hypothesis that "pro-testis/anti-ovary" or "pro-ovary/anti-testis" genetic pathways exist. ${ }^{4-6}$ These children typically present with virilized genitalia due to testosterone production from the presence of testicular tissue. Many individuals with TDSD and a minority with OTDSD have a translocation of the testis-determining $S R Y$ gene, usually onto one of the $\mathrm{X}$ chromosomes, whereas a small proportion have chromosomal rearrangements associated with upregulation (gain-of-function) of $S O X$ gene expression (e.g., duplications of the RevSex [MIM: 616425] enhancer of SOX9 [MIM: 608160] and rearrangements of the SOX3 locus [MIM: 800833]). ${ }^{5,6}$ This ectopic SOX gene expression increases "pro-testis" factors in the early developing ovary and results in a reprogramming of cellular sex identity to testis-typical Sertoli cells. Other rare forms of 46,XX DSD can occur due to mutations (loss-of-function) involving genes that are "pro-ovary/anti-testis." The best example of this is in the WNT4/RSPO1 signaling pathway, which stabilizes $\beta$-catenin and is required for ovary development. $^{7}$ Very rare heterozygous or homozygous mutations in WNT4 (MIM: 603490) cause Müllerian aplasia/hyperandrogenism (MIM: 158330) ${ }^{8}$ or testis development (SERKAL syndrome [MIM: 611812]) in 46,XX individuals, respectively, whereas homozygous RSPO1 (MIM: 609595) mutations are also associated with testis formation and skin phenotypes in 46,XX children (MIM: 610644). ${ }^{7}$ FOXL2

\footnotetext{
${ }^{1}$ Human Developmental Genetics, Institut Pasteur, Paris 75724, France; ${ }^{2}$ Department of Growth and Reproduction, Rigshospitalet, Copenhagen 2100, Denmark; ${ }^{3}$ Department of Medical Genetics, Hospital Trousseau-APHP, Paris 75012, France; ${ }^{4}$ Heim Pál Children's Hospital, Budapest 1089, Hungary; ${ }^{5}$ First Department of Pathology and Experimental Cancer Research, Semmelweis University, Budapest, Hungary; ${ }^{6}$ Department of Pediatrics, Semmelweis University, Budapest 1085, Hungary; ${ }^{7}$ Pediatric and Visceral Surgery and Urology, Hopital Robert Debre, Paris 75019, France; ${ }^{8}$ Endocrinologie et Diabetologie Pediatrique, Hopital Robert Debre, Paris 75019, France; ${ }^{9}$ Division of Genetics, Department of Pediatrics, McGovern Medical School, University of Texas, Houston, TX 77030, USA; ${ }^{10}$ UCL GOSH Institute of Child Health, London WC1N 1EH, UK

*Correspondence: kenmce@pasteur.fr

https://doi.org/10.1016/j.ajhg.2018.01.021.

(C) 2018 The Authors. This is an open access article under the CC BY license (http://creativecommons.org/licenses/by/4.0/).
} 
(MIM: 605597) is a forkhead/winged helix transcription factor, which is also a potential "pro-ovary" and "antitestis" gene. Goat XX fetuses lacking Foxl2 have gonads resembling testes and the induced absence of Foxl2 in adult $\mathrm{XX}$ mice results in trans-differentiation of the ovaries into a testis-like gonad. ${ }^{9-11}$ In humans, heterozygous loss-of-function FOXL2 mutations are associated with autosomal-dominant blepharophimosis-ptosis-epicanthus inversus syndrome (BPES [MIM: 110100]) either with (type I) or without (type 2) ovarian insufficiency as well as ovarian insufficiency without BPES (MIM: 608996), but homozygous FOXL2 disruption has not been described. ${ }^{10}$ The limited understanding of the genes involved in ovary formation means that for most children with OTDSD/TDSD, the molecular basis is currently unknown.

Here, we report the molecular etiology of a syndromic form of 46,XX DSD that includes genital virilization, congenital heart disease (CHD), and variable somatic anomalies including BPES and congenital diaphragmatic hernia $(\mathrm{CDH})$. This syndrome is caused by protein-truncating mutations in the orphan nuclear receptor NR2F2 (MIM: 107773). NR2F2 encodes the transcription factor chicken ovalbumin upstream promoter transcription factor 2 (COUP-TF2). ${ }^{12}$ Our data indicate that in the early developing human chromosomal female XX gonad, COUP-TF2 is a human "pro-ovary" and "anti-testis" sexdetermining factor.

Following written informed consent and with local ethics committee approvals, whole-exome sequencing was performed on 6946 ,XX individuals with either unexplained virilization $(\mathrm{n}=14)$ or unexplained OTDSD/TDSD $(\mathrm{n}=55)$ as described elsewhere. ${ }^{13}$ Sanger sequencing of NR2F2 was performed on DNA from a further 10 individuals with 46,XX OTDSD/TDSD where there was insufficient DNA for complete exome analysis. Exclusion criteria included rearrangements involving SOX genes, mutations in either WNT4 or RSPO1, proven or suspected congenital adrenal hyperplasia (CAH), or the presence of $S R Y$. All samples underwent array comparative genomic hybridization to confirm normal ploidy. Of the 79 children studied, 74 had no additional syndromic features. Of the 5 children with additional features, 3 were unrelated children with OTDSD/TDSD and CHD (with or without BPES), one had 46,XX TDSD with cerebral leukodystrophy, and another had 46,XX TDSD with multiple congenital anomalies, learning difficulties, and alopecia.

Analysis of exome sequencing datasets identified two individuals (individuals 1 and 2) with near-identical heterozygous frameshift mutations in NR2F2 (GenBank: NM_021005.3), c.103_109delGGCGCCC (p.Gly35Argfs* 75), and c.97_103delCCGCCCG (p.Pro33Alafs*77) (Table 1). These mutations were not present in parental DNA and hence are de novo. No other shared genes carrying de novo mutations were identified in the datasets. The mutations are predicted to result in the generation of a downstream termination codon (Figures 1A and 1F). Both children presented with suspected OTDSD/TDSD (Table 1) and congenital heart disease (CHD). Individual 1 had a left congenital diaphragmatic hernia $(\mathrm{CDH})$ and died shortly after birth due to hypoplasia of the left heart. Analysis of an additional 10 individuals with 46,XX OTDSD/TDSD, for whom there was insufficient DNA for complete exome studies, revealed a third unrelated child with OTDSD and CHD harboring the c.97_103delCCGCCCG (p.Pro33Alafs*77) mutation (Table 1 , individual 3). Since the parents of this child were unavailable for study, the mode of transmission of the mutation is unknown. The diagnosis of $46, \mathrm{XX}$ OTDSD was confirmed by histology of the gonad (Figure 1B). Individuals 2 and 3 also had BPES (Figure 1C). In all three children, potentially pathogenic mutations were not identified in any other genes known to be involved in DSD and high-resolution array comparative genomic hybridization (aCGH) did not indicate rearrangements involving DSD-associated genes. These frameshift mutations are absent from the public variant databases and they were detected only in the three individuals in the cohort who had cardiac anomalies together with 46,XX DSD.

NR2F2 is one the most conserved genes in the human genome and is intolerant to protein-truncating variants. ${ }^{14}$ To exclude the possibility that these NR2F2 mutations may be a chance finding, we performed Fisher's exact tests (two-tailed) on the frequency of protein-truncating mutations found in the case subjects and compared this to rare missense mutations from 6,489 control European American and African American cohorts in the NHLBI-ESP project. A rare variant is defined as a variant with an allelic frequency of $<1 \%$ in publically available databases. We found no protein-truncating mutations present in the control populations. We found a highly significant enrichment for the NR2F2 protein-truncating mutations identified in the three 46,XX DSD-affected case subjects compared to the absence of protein-truncating mutations in the control cohort (Fisher's exact test, two-tailed $\left.\mathrm{p}=1.1 \times 10^{-6}\right)$. Even if we consider the five missense mutations present in the control population, the finding of three frameshift mutations in the $46, \mathrm{XX}$ DSD cohort is still highly significant ( $\mathrm{p}=$ $6 \times 10^{-5}$ ). The genetic evidence in favor of causality is more compelling when one considers that the proteintruncating mutations were specifically identified only in the three children presenting with CHD and 46,XX DSD $\left(\mathrm{p}=2.44 \times 10^{-8}\right)$.

NR2F2 encodes a key nuclear receptor, COUP-TF2. ${ }^{12}$ All three frameshift mutations are present in the $\mathrm{N}$-terminal region of the protein and result in a downstream premature termination codon. RNA containing these mutations is predicted to be degraded by nonsense-mediated decay. Even if a truncated protein is produced, it would have severely impaired biological activity since the protein would lack both the DNA- and ligand-binding domains (Figure 1F). An in silico analysis of the NR2F2 exon 1 with 


\begin{tabular}{|c|c|c|c|}
\hline Variable & Individual 1 & Individual 2 & Individual 3 \\
\hline Ancestry & Latino & Senegalese & Hungarian \\
\hline Karyotype & 46,XX SRY-negative & 46,XX SRY-negative & 46,XX SRY-negative \\
\hline Birth weight (kg) & 2.6 & 2.05 & N/A \\
\hline Cardiac & $\begin{array}{l}\text { hypoplastic L heart at birth; severely } \\
\text { dilated R ventricle with moderate RVH } \\
\text { and mild to moderately depressed RV } \\
\text { systolic function }\end{array}$ & persistent ostium secundum and ASD & $\begin{array}{l}\text { VSD at birth; spontaneous closure } \\
\text { of VSD at } 9 \text { years of age }\end{array}$ \\
\hline External genitalia & $\begin{array}{l}\text { male, hyperpigmented; phallus } 3 \mathrm{~cm} \\
\text { with no hypospadias; gonads not } \\
\text { palpable }\end{array}$ & $\begin{array}{l}\text { "ambiguous" with phallus-like clitoris, } \\
\text { pigmented scrotum; gonads not palpable }\end{array}$ & $\begin{array}{l}\text { "ambiguous" Prader IV, pigmented } \\
\text { scrotum, phallus-like clitoris; } \\
\text { R, palpable gonad in the inguinal canal }\end{array}$ \\
\hline Internal genitalia & uterus not identified by US & uterus present & $\begin{array}{l}\mathrm{R} \text {, ductus-like Wolffian structures; } \\
\mathrm{L} \text {, uterus, ovary, and Fallopian tube; } \\
\text { vagina and short urogenital sinus }\end{array}$ \\
\hline Gonads & not observed by US & not observed by US or MRI & $\begin{array}{l}\text { pelvic ultrasound: R testis, L ovary; } \\
\text { histology: R gonad, testis tubules, } \\
\text { and ovarian tissue with oocytes }\end{array}$ \\
\hline $\begin{array}{l}\text { Other somatic } \\
\text { anomalies }\end{array}$ & left congenital diaphragmatic hernia & BPES & $\begin{array}{l}\text { mild learning disabilities, minor limb } \\
\text { anomalies, hypertelorism, BPES }\end{array}$ \\
\hline $\begin{array}{l}\text { Endocrine data } \\
\text { (reference values) }\end{array}$ & $\begin{array}{l}\text { Day 1: T, } 135 \mathrm{ng} / \mathrm{dL}(20-64) ; 17-\mathrm{OHP}, \\
120 \mathrm{ng} / \mathrm{dL}(11-170) ; \mathrm{LH}, 5.1 \mathrm{IU} / \mathrm{L} \\
(0.02-7.0) ; \mathrm{FSH}, 1.1 \mathrm{IU} / \mathrm{L}(0.16-4.1)\end{array}$ & $\begin{array}{l}\text { Day 11: T, } 579 \mathrm{ng} / \mathrm{dL}(<130) ; \mathrm{AMH}, 44 \mathrm{ng} / \mathrm{mL} \\
(<4.2) ; \text { Inhibin B, } 263 \mathrm{pg} / \mathrm{mL}(<110) ; \mathrm{FSH}, \\
\text { 13.2 IU/L }(<10) ; \mathrm{LH}, 9.3 \mathrm{IU} / \mathrm{L}(0.9-3) ; \\
\text { 17-OHP, } 127 \mathrm{ng} / \mathrm{dL}(<270) \\
\text { Day 15: T, } 327 \mathrm{ng} / \mathrm{dL}(<40) ; \\
\text { AMH, } 43.1 \mathrm{ng} / \mathrm{mL}(<4.2) ; \mathrm{Inhibin} \mathrm{B}, \\
217 \mathrm{pg} / \mathrm{mL}(<110) ; \mathrm{FSH}, 6.9 \mathrm{IU} / \mathrm{L}(<10) ; \mathrm{LH} \text {, } \\
5.1 \mathrm{IU} / \mathrm{L}(0.9-3) ; \text { estradiol }<5 \mathrm{pg} / \mathrm{mL} \\
1 \mathrm{month} \text { T, } 304 \mathrm{ng} / \mathrm{dL}(<40) ; \mathrm{AMH}, \\
43.1 \mathrm{ng} / \mathrm{mL}(<4.2) ; \mathrm{Inhibin} \mathrm{B}, 230 \mathrm{pg} / \mathrm{mL} \\
(<110) ; \mathrm{FSH}, 9 \mathrm{IU} / \mathrm{L}(<10) ; \mathrm{LH}, 15.5 \mathrm{IU} / \mathrm{L} \\
(0.9-3) ; \text { estradiol, }<5 \mathrm{pg} / \mathrm{mL}\end{array}$ & $\begin{array}{l}\text { Day 17: T, } 250 \mathrm{ng} / \mathrm{dL}(<40) ; \\
\text { 17-OHP, } 185 \mathrm{ng} / \mathrm{dL}(40-490) \\
\text { Day 30: T, } 460 \mathrm{ng} / \mathrm{dL}(<40) \\
\text { Day 45: T, } 50 \mathrm{ng} / \mathrm{dL}(<40) \\
\text { Day 73: T, } 110 \mathrm{ng} / \mathrm{dL}(<40)\end{array}$ \\
\hline Mutation & $\begin{array}{l}\text { de novo, c.103_109delGGCGCCC } \\
\text { (p.Gly35Argfs*75) }\end{array}$ & $\begin{array}{l}\text { de novo, c.97_103delCCGCCCG } \\
\text { (p.Pro33Alafs*77) }\end{array}$ & $\begin{array}{l}\text { N/A, c.97_103delCCGCCCG } \\
\text { (p.Pro33Alafs*77) }\end{array}$ \\
\hline \multicolumn{4}{|c|}{$\begin{array}{l}\text { Normal range refers to the range of basal levels in control subjects matched according to age and chromosomal sex with the case subjects. Conversion factors } \\
\text { testosterone ng/dL } \times 0.034 \text { for } \mathrm{nmol} / \mathrm{L} ; 17-\mathrm{OHP} \mathrm{ng} / \mathrm{dL} \times 0.0303 \text { for } \mathrm{nmol} / \mathrm{L} ; \mathrm{AMH} \mathrm{ng} / \mathrm{mL} \times 7.14 \mathrm{for} \mathrm{pmol} / \mathrm{L} ; \text { estradiol } \mathrm{pg} / \mathrm{mL} \times 3.67 \mathrm{for} \mathrm{pmol} / \mathrm{L} \text {. } \\
\text { Abbreviations: L, left; R, right; RVH, right ventricular hypertrophy; US, ultrasound; T, testosterone; } 17-\mathrm{OHP}, 17-\mathrm{hydroxyprogesterone;} \mathrm{LH,} \mathrm{luteinizing} \mathrm{hormone} \\
\text { FSH, follicle-stimulating hormone; ASD, atrial septal defect; MRI, magnetic resonance imaging; BPES, blepharophimosis ptosis epicanthus inversus syndrome } \\
\text { AMH, anti-Müllerian hormone; VSD, ventricular septal defect; N/A, not available. Individual } 1 \text { had a male-typical phenotype and high testosterone consisten } \\
\text { with testicular tissue; individual } 2 \text { had high AMH and inhibin B and high testosterone consistent with testicular tissue; individual } 3 \text { had high testosterone anc } \\
\text { histological evidence of testicular tissue. In all situations, biochemical and genetic testing for other causes of virilization such as congenital adrenal hyperplasia } \\
\text { (e.g., 17-OHP) were negative. }\end{array}$} \\
\hline
\end{tabular}

either of the two deletions using the tools Human Splicing Factor 3 (HSF3), Splice Predictor, and RegRNA indicated that neither the two deletions are predicted to generate cryptic splice sites.

Murine Coup-tf2 protein has been reported to accumulate during early ovary development in a distinct Foxl2-negative somatic cell precursor. ${ }^{15}$ Although data are limited, these cells with Coup-tf 2 have been hypothesized to be either mesenchymal cells and/or to differentiate into theca cells. ${ }^{15}$ We therefore investigated the profile of protein localization of COUP-TF2 in the early developing human ovary. Human fetal ovaries were isolated from material available following elective termination of pregnancy during the first trimester at the Department of Gynaecology at Copenhagen University Hospital (Rigshospitalet) and Hvidovre Hospital, Denmark. The regional ethics committee approved this study (permit number H-1-2012-007) and women gave their informed written and oral consent. We observed widespread presence of COUP-TF2 in the stromal cell population of the ovary at gestational weeks (GW) $9+1$ (Figures 2A-2C) and GW 9+5 (Figures 2D and 2E), whereas FOXL2 is limited to somatic cells of the fetal ovary (Figure 2). At these stages, co-immunofluorescence demonstrated that FOXL2 and COUP-TF2 appeared to be mutually exclusive at the cellular level (Figure 2). Furthermore, analysis of RNA expression in different tissues from adults reveals that NR2F2 is most highly expressed in the ovary and female reproductive tissues. ${ }^{16}$

We provide compelling genetic evidence for a role of COUP-TF2 in early human ovary development. We identified three protein-truncating, complete loss-of-function mutations that are acting in a dominant fashion. These findings indicate that NR2F2 may function in a dosage-sensitive manner, which is similar to other gene 


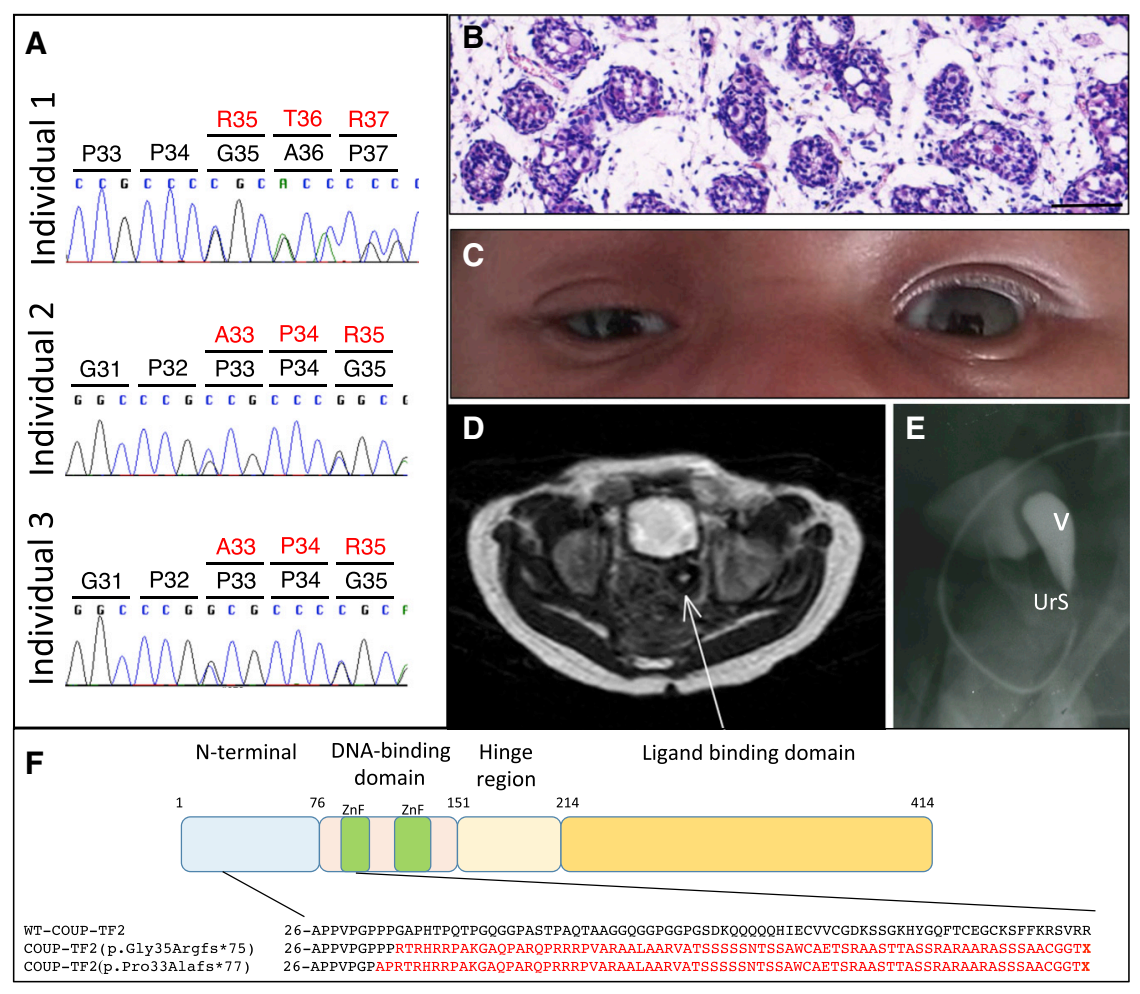

Figure 1. Identification of Three Individuals with 46,XX DSD and Heterozygous Frameshift Mutations in NR2F2

(A) Representative Sanger sequence chromatograms of individuals 1-3 showing the positions of the frameshift mutations. (B) Histology of the right gonad of individual 3 showing testicular tubule-like structures surrounded by stromal-like tissue (scale bar corresponds to $100 \mu \mathrm{m}$ ).

(C) Blepharophimosis-ptosis-epicanthus inversus syndrome (BPES) of individual 3.

(D) Uterus (arrow) of individual 2 observed by MRI.

(E) Pelvic radiography of individual 3 showing the vagina (V) and a short urogenital sinus (UrS).

(F) Schematic representation of COUP-TF2 showing the main functional domains and the position and downstream consequences of the three frameshift mutations. The first zinc finger motif is highlighted in green in the sequence alignment. The transcript ID is GenBank: NM_021005.3.

The BPES phenotype observed in children with NR2F2 mutations is strikingly similar to that associated with dominant mutations in FOXL2.

mutations known to disrupt human sex determination. This indicates that COUP-TF2 may be required to establish ovary identity during early human gonad development by the repression of genes involved in testis determination.

In mice, Coup-Tf2 is involved in the development of multiple organs and tissues by modulating the expression of downstream targets to promote cellular differentiation, proliferation, migration, survival, and intercellular communication. ${ }^{12,17-20}$ Globally, Coup-tf2 is highly abundant at E14-E15 in the mesenchymal compartment of the developing organs and declines after the completion of organogenesis. ${ }^{12}$ The absence of Coup-tf 2 in terminally differentiated epithelium suggests that Coup-tf2 plays a major role in the mesenchymal-epithelial transition. Mice lacking Coup-tf2 die around E10 due to defects of angiogenesis and heart development. ${ }^{20}$ Recently, ten human heterozygous missense, in-frame duplication, or splice donor mutations in NR2F2 were reported in association with cardiac defects (CHD [MIM: 615779]). ${ }^{21,22}$ Of these mutations, four were confirmed as de novo. Most children with NR2F2 mutations had atrioventricular septal defects, including a child with a hypoplastic left heart, which is consistent with the cardiac phenotypes of the children in this study. However, non-cardiac defects, such as virilization or BPES, were not described in these cohorts. In our study, individual 1 also presented with a left-sided diaphragmatic hernia $(\mathrm{CDH})$. The p.Pro33Alafs*77 variant was reported in a child with ASD, exotropia, and left-sided $\mathrm{CDH}$, suggesting that $\mathrm{CDH}$ is part of the phenotypic spectrum associated with NR2F2 mutations. ${ }^{23}$
These pathogenic variants cause BPES frequently together with $46, \mathrm{XX}$ premature ovarian insufficiency but testis development has not been reported. BPES is thought to originate following developmental defects in peri-ocular mesenchymal cells, which are required to form the levator smooth muscle, tarsus, and Meibomian glands. Coup-tf 2 is known to play crucial roles in the formation of the morphology of the murine eye, and given the similarities in the phenotypes, it would be of interest to determine whether FOXL2 and COUP-TF2 are acting in the same developmental pathway. ${ }^{24}$

In contrast to cardiac development, the role(s) of COUP-TF2 in early gonad development has yet to be fully defined. In the developing fetal rat testis, partial inhibition of Coup-tf 2 by phthalates causes expansion of Leydig cells and an increase in the intratesticular testosterone concentration, consistent with Coup-tf2 being a factor repressing fetal androgenization. ${ }^{19}$ The protein localization of COUP-TF2 in human fetal Leydig cells during the first and second trimester could also be consistent with a similar role of COUP-TF2 in repression of androgen production. ${ }^{19,25}$ Indeed, there is a large body of evidence from early studies to indicate that COUP-TF2 functions as a transcriptional repressor of pro-testis genes. ${ }^{26}$

Data are also emerging for the role of Coup-Tf2 in female reproductive development in mice but there seem to be clear differences with humans. Murine Coup-Tf2 $2^{+-} \mathrm{XX}$ females show a wide range of reproductive anomalies including reduced fecundity, irregular estrus cycles, delayed puberty, retarded postnatal growth, and reduced levels of steroidogenic enzymes, but virilization and testis 

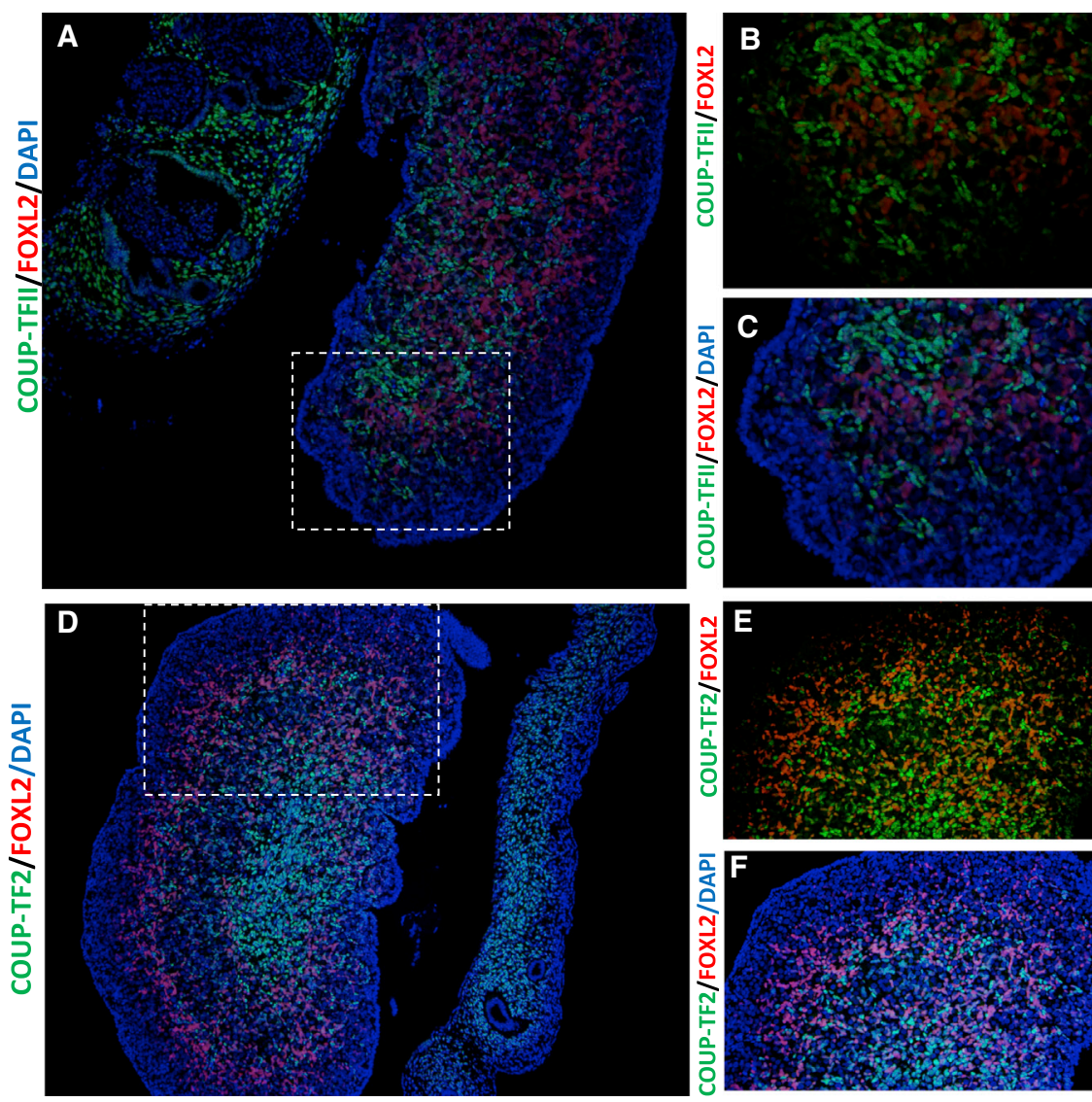

Figure 2. Protein Localization of COUP. TF2 and FOXL2 during Early Human Ovarian Development

(A-C) Immunofluorescence showing protein localization of COUP-TF2 (green) and FOXL2 (red) at gestational week (GW) 9+1. (D-F) Immunohistochemistry at GW 9+5. Extensive staining of COUP-FT2 is observed in the stromal cell population of the developing fetal ovary. At both stages there appears to be a mutually exclusive presence of FOXL2 and NR2F2, suggesting they mark different somatic cell populations. Dashed box in (A) and (C) indicates the position of the expanded views. Nuclei are counterstained with DAPI. Fetal age was determined by scanning crown-rump length and by evaluation of foot length. ${ }^{34}$ Sex of fetal samples was determined by PCR for $S R Y$ as previously reported. ${ }^{35}$ Immunofluorescence was performed as previously described. ${ }^{36}$ Primary antibodies used were COUP-TFII/NR2F2 (Perseus Proteomics, PP-H7147-60, diluted 1:100) and FOXL2 (a kind gift from Dagmar Wilhelm, diluted 1:100). Negative controls were included and processed with the primary antibody replaced by the dilution buffer alone. None of the negative control slides showed staining. Fluorescent images were captured using an Olympus BX61 microscope (Olympus) with the Cell Sens Dimension software v.1.16. development has not been reported. ${ }^{27}$ Recently, a tamoxifen-inducible $\mathrm{Wt} 1^{\text {CreERT2 }}$ mouse model that targets $\mathrm{Nr} 2 f 2$ in $\mathrm{Wt}^{+}$mesenchymal cells was described, where knockout XX mice had both Müllerian and Wolffian ducts in the mesonephros. ${ }^{28}$ The ovaries of the mice lacking Nr2f2 did not produce androgens, but an androgen-independent activation of the p-ERK pathway in the Wolffian duct epithelium was observed, leading to its maintenance in XX mice. In striking contrast to the mouse model, virilization of the genitalia in the three children reported here was associated with elevated levels of both testosterone and $\mathrm{AMH}$ and in one child the presence of testicular tissue was confirmed by gonad histology.

The mechanism responsible for testis development associated with COUP-TF2 variants remains to be defined. Consistent with the $Z$-theory of a double repressor model of human sex determination, COUP-TF2 acts both positively and negatively to modulate the expression of genes involved in sex determination in other cellular and organ contexts. For example, in the human endometrium, COUP-TF2 is a positive regulator of the pro-ovary WNT4 gene and in mice Coup-tf2 negatively regulates the expression of the pro-testis Sox9 gene in the osteogenic mesenchyme. $^{29,30}$

In addition to revealing unforeseen mechanisms in sex development, our study also highlights the importance of nuclear receptors (NR) in human development and disease. Humans have 48 different NRs with a diverse range of functions and next-generation sequencing approaches are starting to identify novel and sometimes unexpected phenotypes associated with specific NR variants. ${ }^{31}$ Recently, we described recurrent missense mutations that specifically target the Arg92 residue of another nuclear receptor, NR5A1 and which are associated with both 46,XX OTDSD and TDSD in multiple individuals. ${ }^{32}$ When this mutation is introduced into the XX mouse, it does not result in testis formation. ${ }^{33}$ The data presented here provide additional evidence of the emerging importance of nuclear receptors in establishing human ovarian identity and indicate that nuclear receptors may have divergent functions in mouse and human biology.

\section{Acknowledgments}

A.B. is funded in part by the program Actions Concertees Interpasteuriennes (ACIP) and a research grant from the European Society of Pediatric Endocrinology. A.B. and K.McE. are funded by a research grant from the EuroDSD in the European Community's Seventh Framework Programme FP7/2007-2013 under grant agreement no. 201444 as well as grant no. 295097 as part of the EU call FP7-INCO-2011-6. J.C.A. is a Wellcome Trust Senior Research Fellow in Clinical Science (grant 098513/Z/12/Z, 209328/Z/17/Z) with research support from Great Ormond Street Hospital Children's Charity (grant V2518) and the NIHR GOSH BRC (IS-BRC-1215-20012). The views expressed are those of the author(s) and not necessarily those of the NHS, the NIHR, or the Department of Health. This work is supported by the COST Action 
DSDnet BM1303. The authors wish to thank Dr. Etienne Patin for comments on the manuscript. This work was funded by the Agence Nationale de la Recherche (Laboratoire d'Excellence Revive, Investissement d'Avenir; ANR-10-LABX-73).

Received: November 20, 2017

Accepted: January 26, 2018

Published: February 22, 2018

\section{Web Resources}

ExAC Browser, http://exac.broadinstitute.org/

GenBank, https://www.ncbi.nlm.nih.gov/genbank/

Human Splicing Finder, http://www.umd.be/HSF3/

NetGene2, http://www.cbs.dtu.dk/services/NetGene2/

NHLBI Exome Sequencing Project (ESP) Exome Variant Server, http://evs.gs.washington.edu/EVS/

OMIM, http://www.omim.org/

RegRNA, http://regrna.mbc.nctu.edu.tw/html/prediction.html

The Human Protein Atlas, https://www.proteinatlas.org/ ENSG00000185551-NR2F2/tissue

\section{References}

1. Bashamboo, A., and McElreavey, K. (2013). Gene mutations associated with anomalies of human gonad formation. Sex Dev. 7, 126-146.

2. Del Valle, I., Buonocore, F., Duncan, A.J., Lin, L., Barenco, M., Parnaik, R., Shah, S., Hubank, M., Gerrelli, D., and Achermann, J.C. (2017). A genomic atlas of human adrenal and gonad development. Wellcome Open Res. 2, 25.

3. McElreavey, K., Vilain, E., Abbas, N., Herskowitz, I., and Fellous, M. (1993). A regulatory cascade hypothesis for mammalian sex determination: SRY represses a negative regulator of male development. Proc. Natl. Acad. Sci. USA 90, 3368-3372.

4. Lee, P.A., Nordenström, A., Houk, C.P., Ahmed, S.F., Auchus, R., Baratz, A., Baratz Dalke, K., Liao, L.M., Lin-Su, K., Looijenga, L.H., 3rd., et al.; Global DSD Update Consortium (2016). Global disorders of sex development update since 2006: perceptions, approach and care. Horm. Res. Paediatr. $85,158-180$.

5. Ohnesorg, T., van den Bergen, J.A., Belluoccio, D., ShankaraNarayana, N., Kean, A.M., Vasilaras, A., Ewans, L., Ayers, K.L., and Sinclair, A.H. (2017). A duplication in a patient with 46,XX ovo-testicular disorder of sex development refines the SOX9 testis-specific regulatory region to $24 \mathrm{~kb}$. Clin. Genet. 92, 347-349.

6. Sutton, E., Hughes, J., White, S., Sekido, R., Tan, J., Arboleda, V., Rogers, N., Knower, K., Rowley, L., Eyre, H., et al. (2011). Identification of SOX3 as an XX male sex reversal gene in mice and humans. J. Clin. Invest. 121, 328-341.

7. Biason-Lauber, A., and Chaboissier, M.C. (2015). Ovarian development and disease: The known and the unexpected. Semin. Cell Dev. Biol. 45, 59-67.

8. Biason-Lauber, A., Konrad, D., Navratil, F., and Schoenle, E.J. (2004). A WNT4 mutation associated with Müllerian-duct regression and virilization in a $46, \mathrm{XX}$ woman. N. Engl. J. Med. 351, 792-798.

9. Boulanger, L., Pannetier, M., Gall, L., Allais-Bonnet, A., Elzaiat, M., Le Bourhis, D., Daniel, N., Richard, C., Cotinot, C.,
Ghyselinck, N.B., and Pailhoux, E. (2014). FOXL2 is a female sex-determining gene in the goat. Curr. Biol. 24, 404-408.

10. Elzaiat, M., Todeschini, A.L., Caburet, S., and Veitia, R.A. (2017). The genetic make-up of ovarian development and function: the focus on the transcription factor FOXL2. Clin. Genet. 91, 173-182.

11. Uhlenhaut, N.H., Jakob, S., Anlag, K., Eisenberger, T., Sekido, R., Kress, J., Treier, A.C., Klugmann, C., Klasen, C., Holter, N.I., et al. (2009). Somatic sex reprogramming of adult ovaries to testes by FOXL2 ablation. Cell 139, 1130-1142.

12. Wu, S.P., Yu, C.T., Tsai, S.Y., and Tsai, M.J. (2016). Choose your destiny: Make a cell fate decision with COUP-TFII. J. Steroid Biochem. Mol. Biol. 157, 7-12.

13. Murphy, M.W., Lee, J.K., Rojo, S., Gearhart, M.D., Kurahashi, K., Banerjee, S., Loeuille, G.A., Bashamboo, A., McElreavey, K., Zarkower, D., et al. (2015). An ancient protein-DNA interaction underlying metazoan sex determination. Nat. Struct. Mol. Biol. 22, 442-451.

14. Lek, M., Karczewski, K.J., Minikel, E.V., Samocha, K.E., Banks, E., Fennell, T., O’Donnell-Luria, A.H., Ware, J.S., Hill, A.J., Cummings, B.B., et al.; Exome Aggregation Consortium (2016). Analysis of protein-coding genetic variation in 60,706 humans. Nature 536, 285-291.

15. Rastetter, R.H., Bernard, P., Palmer, J.S., Chassot, A.A., Chen, H., Western, P.S., Ramsay, R.G., Chaboissier, M.C., and Wilhelm, D. (2014). Marker genes identify three somatic cell types in the fetal mouse ovary. Dev. Biol. 394, 242-252.

16. Uhlén, M., Fagerberg, L., Hallström, B.M., Lindskog, C., Oksvold, P., Mardinoglu, A., Sivertsson, A., Kampf, C., Sjöstedt, E., Asplund, A., et al. (2015). Proteomics. Tissuebased map of the human proteome. Science 347, 1260419.

17. Pereira, F.A., Qiu, Y., Zhou, G., Tsai, M.J., and Tsai, S.Y. (1999). The orphan nuclear receptor COUP-TFII is required for angiogenesis and heart development. Genes Dev. 13, 1037-1049.

18. Yu, C.T., Tang, K., Suh, J.M., Jiang, R., Tsai, S.Y., and Tsai, M.J. (2012). COUP-TFI is essential for metanephric mesenchyme formation and kidney precursor cell survival. Development 139, 2330-2339.

19. van den Driesche, S., Walker, M., McKinnell, C., Scott, H.M., Eddie, S.L., Mitchell, R.T., Seckl, J.R., Drake, A.J., Smith, L.B., Anderson, R.A., and Sharpe, R.M. (2012). Proposed role for COUP-TFII in regulating fetal Leydig cell steroidogenesis, perturbation of which leads to masculinization disorders in rodents. PLoS ONE 7, e37064.

20. Lin, F.J., You, L.R., Yu, C.T., Hsu, W.H., Tsai, M.J., and Tsai, S.Y. (2012). Endocardial cushion morphogenesis and coronary vessel development require chicken ovalbumin upstream promoter-transcription factor II. Arterioscler. Thromb. Vasc. Biol. 32, e135-e146.

21. Al Turki, S., Manickaraj, A.K., Mercer, C.L., Gerety, S.S., Hitz, M.P., Lindsay, S., D'Alessandro, L.C.A., Swaminathan, G.J., Bentham, J., Arndt, A.K., et al.; UK10K Consortium (2014). Rare variants in NR2F2 cause congenital heart defects in humans. Am. J. Hum. Genet. 94, 574-585.

22. Li, A.H., Hanchard, N.A., Furthner, D., Fernbach, S., Azamian, M., Nicosia, A., Rosenfeld, J., Muzny, D., D’Alessandro, L.C.A., Morris, S., et al. (2017). Whole exome sequencing in 342 congenital cardiac left sided lesion cases reveals extensive genetic heterogeneity and complex inheritance patterns. Genome Med. 9, 95.

23. High, F.A., Bhayani, P., Wilson, J.M., Bult, C.J., Donahoe, P.K., and Longoni, M. (2016). De novo frameshift mutation in 
COUP-TFII (NR2F2) in human congenital diaphragmatic hernia. Am. J. Med. Genet. A. 170, 2457-2461.

24. Tang, K., Tsai, S.Y., and Tsai, M.J. (2015). COUP-TFs and eye development. Biochim. Biophys. Acta 1849, 201-209.

25. Lottrup, G., Nielsen, J.E., Maroun, L.L., Møller, L.M., Yassin, M., Leffers, H., Skakkebæk, N.E., and Rajpert-De Meyts, E. (2014). Expression patterns of DLK1 and INSL3 identify stages of Leydig cell differentiation during normal development and in testicular pathologies, including testicular cancer and Klinefelter syndrome. Hum. Reprod. 29, 1637-1650.

26. Yu, R.N., Ito, M., and Jameson, J.L. (1998). The murine Dax-1 promoter is stimulated by SF-1 (steroidogenic factor-1) and inhibited by COUP-TF (chicken ovalbumin upstream promoter-transcription factor) via a composite nuclear receptorregulatory element. Mol. Endocrinol. 12, 1010-1022.

27. Takamoto, N., Kurihara, I., Lee, K., Demayo, F.J., Tsai, M.J., and Tsai, S.Y. (2005). Haploinsufficiency of chicken ovalbumin upstream promoter transcription factor II in female reproduction. Mol. Endocrinol. 19, 2299-2308.

28. Zhao, F., Franco, H.L., Rodriguez, K.F., Brown, P.R., Tsai, M.J., Tsai, S.Y., and Yao, H.H. (2017). Elimination of the male reproductive tract in the female embryo is promoted by COUP-TFI in mice. Science 357, 717-720.

29. Li, X., Large, M.J., Creighton, C.J., Lanz, R.B., Jeong, J.W., Young, S.L., Lessey, B.A., Palomino, W.A., Tsai, S.Y., and Demayo, F.J. (2013). COUP-TFII regulates human endometrial stromal genes involved in inflammation. Mol. Endocrinol. 27, 2041-2054.

30. Hsu, W.H., Chen, C.M., and You, L.R. (2017). COUP-TFII is required for morphogenesis of the neural crest-derived tympanic ring. Sci. Rep. 7, 12386.
31. Achermann, J.C., Schwabe, J., Fairall, L., and Chatterjee, K. (2017). Genetic disorders of nuclear receptors. J. Clin. Invest. $127,1181-1192$.

32. Bashamboo, A., Donohoue, P.A., Vilain, E., Rojo, S., Calvel, P., Seneviratne, S.N., Buonocore, F., Barseghyan, H., Bingham, N., Rosenfeld, J.A., et al.; Members of UDN (2016). A recurrent p.Arg92Trp variant in steroidogenic factor-1 (NR5A1) can act as a molecular switch in human sex development. Hum. Mol. Genet. 25, 3446-3453.

33. Miyado, M., Inui, M., Igarashi, M., Katoh-Fukui, Y., Takasawa, K., Hakoda, A., Kanno, J., Kashimada, K., Miyado, K., Tamano, M., et al. (2016). The p.R92W variant of NR5A1/Nr5a1 induces testicular development of 46,XX gonads in humans, but not in mice: phenotypic comparison of human patients and mutation-induced mice. Biol. Sex Differ. 7, 56.

34. Evtouchenko, L., Studer, L., Spenger, C., Dreher, E., and Seiler, R.W. (1996). A mathematical model for the estimation of human embryonic and fetal age. Cell Transplant. $5,453-464$.

35. Jørgensen, A., Nielsen, J.E., Perlman, S., Lundvall, L., Mitchell, R.T., Juul, A., and Rajpert-De Meyts, E. (2015). Ex vivo culture of human fetal gonads: manipulation of meiosis signalling by retinoic acid treatment disrupts testis development. Hum. Reprod. 30, 2351-2363.

36. Mitchell, R.T., Cowan, G., Morris, K.D., Anderson, R.A., Fraser, H.M., Mckenzie, K.J., Wallace, W.H., Kelnar, C.J., Saunders, P.T., and Sharpe, R.M. (2008). Germ cell differentiation in the marmoset (Callithrix jacchus) during fetal and neonatal life closely parallels that in the human. Hum. Reprod. 23, 2755-2765. 